\title{
The Impact of Supervisor Support on Employees' Psychological Wellbeing: A Parallel Mediation Analysis of Work-To-Family Conflict and Job Satisfaction
}

\author{
Erasmus Keli Swanzy ${ }^{1}$ \\ ${ }^{1}$ University of Bologna, Italy \\ Correspondence: Erasmus Keli Swanzy, University of Bologna, Italy.
}

Received: September 9, 2020

Accepted: October 7, 2020

Online Published: October 21, 2020

doi:10.5539/ibr.v13n11p41

URL: https://doi.org/10.5539/ibr.v13n11p41

\begin{abstract}
This study tries to examine the influence of work-to-family conflict and job satisfaction on the relationship between supervisor support and the psychological wellbeing of 290 administrative workers at the University of Cape Coast, Ghana. The results of the parallel mediation analysis showed that supervisor support had a significant positive impact on employees' psychological wellbeing and job satisfaction and also had a significant negative impact on employees' work-to-family conflict. Moreover, the study found a direct positive effect of employees' job satisfaction on their psychological wellbeing but did not find a direct negative effect of employees' work-to-family conflict on their psychological wellbeing. In addition, job satisfaction mediated the association between supervisor support and the psychological wellbeing of employees. The study however found no evidence of the mediating influence of work-to-family conflict on the relationship between supervisor support and employees' psychological wellbeing. Both theoretical and practical implications were further discussed.
\end{abstract}

Keywords: supervisor support, psychological wellbeing, work-to-family conflict and job satisfaction

\section{Introduction}

With the dynamics in technological advancement and it impacts on work and workplace, research on supervisor support has increasingly gained attention by researchers and practitioners in the past few decades particularly with regards to employees' wellbeing. Employees' support they received from their supervisors has turned out to have several impacts on workers' burnout, emotional exhaustion, anxiety and depression which may directly or indirectly affect their overall psychological wellbeing (Kawachi \& Berkman, 2001, Plaisier et al., 2007, Sinokki et al., 2010).

Hence, it is vital for researchers and practitioners to have a comprehensive knowledge of the mechanisms through with supervisor support could affect employees' psychological wellbeing both directly and indirectly. Notwithstanding the fact that extensive studies have been steered on probing the impact of supervisor support on employees' psychological wellbeing (Beehr, Farmer, Glazer, Gudanowski \& Nair, 2003; Gilbreath \& Benson, 2004; Gordon, Tang, Day \& Adler, 2019; Hämmig, 2017; Kawachi \& Berkman, 2001; Plaisier et al., 2007; Rana \& Javed, 2019; Sinokki et al., 2010). However, past investigations that explored the significance of supportive supervisor on employees' psychological wellbeing, have not simultaneously examined the mediating roles of work-to-family conflict and job satisfaction on the effect of supervisor support on employees' psychological wellbeing. Hence it remains to be seen whether work-to-family conflict and job satisfaction can serve as a mediating role in the relationship between supervisor support and employees' psychological wellbeing.

Therefore, bearing in mind the gap left by previous studies that explored supervisor support and workers' psychological wellbeing, this current study seeks to investigate the impact of supervisor support on employees' psychological wellbeing via work-to-family conflict or job satisfaction. This is presumably the first study to examine a parallel mediation analysis of this kind on the association between supervisor support and the psychological wellbeing of employees. Conducting a mediation analysis of this kind will additionally elucidate pathways that will aid us to better understand the probable causal effects and interactions among supervisor support and psychological wellbeing, work-to-family conflict and job satisfaction of employees (Shrout \& Bolger, 2002). 


\section{Literature Review and Hypotheses Development}

\subsection{Supervisor Support}

Eisenberger, Stinglhamber, Vandenberghe, Sucharski \& Rhoades (2002) explained supervisor support as the level in which subordinates are aware that their supervisors care for and value their welfare and input at work. According to Eisenberger et al. (2002), supportive supervisor provides guidance, assistance and feedback to their employees that are crucial to employees' adaptation in the workplace. With guidance, supervisors provide significant directions to their employees to know their responsibilities and how to carry out these responsibilities. With assistance, supervisors assist in removing any obstacles that may impede their employees in performing their duties accurately. Regarding feedback, supervisors provide valuable information that helps employees to improve upon their performance within the working environment. Guidance, assistance and feedback that employees receive from their supervisors had been known to assist employees to cope with complex situations that occur in the workplace, therefore alleviating occupational stress that may affect employees' psychological wellbeing, work-to-family conflict and job satisfaction.

\subsection{The Direct Effect of Supervisor Support on Employees' Psychological Wellbeing}

Psychological wellbeing can be explained as the degree to which an individual is effectively functioning or the general effectiveness of a person's psychological functioning (Ryan \& Deci, 2001; Sekaran, 1985; Wright \& Cropanzano, 2000). Hämmig (2017) suggested the need to consider supervisor support as one of the vital elements in workplace health promotion after conducting a study on 5877 employees and found out that supportive supervisors had a significant influence on their employees' wellbeing. Other studies (Beehr et al., 2003; Gibson, Grey \& Hastings, 2009; Gordon et al., 2019; Rana \& Javed, 2019; Willemse, de Jonge, Smit, Depla \& Pot, 2012) have also found out that supportive supervisors had a significant influence on employees' psychological strain, emotional exhaustion, burnout, anxiety and depressive symptoms which may all contribute to affecting their general psychological wellbeing. In addition, several previous studies (e.g. Gilbreath \& Benson, 2004; Kawachi \& Berkman, 2001; Plaisier et al., 2007) suggest that social support such as support from supervisors tends to have a positive direct effect on employees' psychological wellbeing. Thus, research findings seem to support the relationship between supportive supervisors and psychological wellbeing leading to the testing of the following hypothesis;

H1: Supervisor support will have a significant positive effect on employees' psychological wellbeing.

\subsection{Supportive Supervisors' Impact on Employees' Work-To-Family Conflict}

There have been several definitions of Work/family conflict by many researchers, however, Greenhaus and Beutell (1985) explained it as "a form of inter-role conflict in which the role pressures from the work and family domains are mutually incompatible in some respect" (p. 77). Moreover, this conflict has been known to take two different forms known as work-to-family conflict and family-to-work conflict (Frone, 2003; Michel, Kotrba, Mitchelson, Clark \& Baltes, 2011). Work-to-family conflict is when the work a person does interfere with his or her family roles while family-to-work conflict is when a person's family roles interfere with his or her work. However, Mesmer-Magnus \& Viswesvaran (2005) emphasized that these two forms can be considered separately and be used independently for different studies. Therefore, this current study focuses on employees' work roles interfering with their family roles.

Besides the influence of supervisor support on employees' psychological wellbeing, it has been known that supervisor support can be helpful to employees to cope with their work-to-family conflict (Kossek, Pichler, Bodner \& Hammer, 2011; Selvarajan, Cloninger \& Singh, 2013; Van Daalen, Willemsen \& Sanders, 2006). Ford, Heinen and Langkamer (2007) reported that employees' work-to-family struggles significantly decreases when their supervisors tend to be more supportive of them. This could be attributed to the fact that supportive supervisors are considered as part of social assistance that helps employees in coping with problems related to their work-to-family conflict (Anderson, Coffey \& Byerly, 2002; Burke \& Greenglass, 1999). In addition, Karatepe and Kilic (2007) explored the work-to-family conflict of 886 staff in Northern Cyprus hotels and found that supportive supervisors had a negative impact on staffs' work-to-family conflict. A more recent study conducted by Talukder (2019) also confirmed that supportive supervisors had a significant negative effect on employees' work-to-family conflict. In light of this reviewed literature, the following hypothesis was tested;

H2: Supervisor support will have a significant negative effect on employees' work-to-family conflict.

\subsection{Supportive Supervisors' Impact on Employees' Job Satisfaction}

According to Weiss (2002) job satisfaction can be defined as "a positive (or negative) evaluative judgment one makes about one's job or job situation" (p. 175). Anderson et al. (2002) investigated on supportive supervisors 
and workers' job satisfaction and found that supportive supervisors played a crucial role in determining the degree of job satisfaction of employees. In addition, several studies that have explored on supervisor support and employees' job satisfaction revealed that the support employees received from their supervisor played a crucial role in influencing their job satisfaction (Alegre, Mas-Machuca \& Berbegal-Mirabent, 2016; Gok, Karatuna, \& Karaca, 2015; Karatepe \& Kilic, 2007; Kula \& Guler, 2014; Quresshi \& Hamid, 2017; Sergeant \& Frenkel, 2000). This may be so because workers feel appreciated, respected and supported when their supervisors tend to be more supportive of them. A study done by Quresshi et al. (2018) on the influence of supportive supervisors on job satisfaction of nurses revealed that nurses' degree of job satisfaction was positively influenced by their supervisors' support. In addition, a recent study conducted by Ahmad et al. (2019) also reported that supervisor support had a significant positive influence on employees' job satisfaction, hence leading to the testing of the following hypothesis;

H3: Supervisor support will have a significant positive effect on employees' job satisfaction.

\subsection{Work-family Conflict as a Direct Antecedent of Psychological Wellbeing}

Past studies that have explored on employees' work-family conflict have shown that employees' struggles with their work and family roles have a significant effect on several employees' outcomes including psychological wellbeing (Allen, Herst, Bruck \& Sutton, 2000; Frone, 2003; Hill, 2005; Kalliath, Kalliath \& Chan, 2017; Obrenovic, Du Jianguo \& Khan, 2020; Winefield, Boyd \& Winefield, 2014). This may be because work-to-family conflict is considered a stressor that affects employees' psychological wellbeing. Accordingly, Lu, Gilmour, Kao and Huang (2006) provided further insights on the influence of work-to-family conflict on employees' psychological wellbeing after conducting a cross-cultural study using British and Taiwanese employees. The study findings showed that employees' struggles with their work and family roles had undesirable effects on employees' psychological wellbeing hence leading to the testing of the following hypothesis;

H4: Employees' work-to-family conflict will have a significant negative effect on their psychological wellbeing.

\subsection{Job Satisfaction as a Direct Antecedent of Psychological Wellbeing}

Much the same as work-to-family conflict, past studies have also reported the significant effect of job satisfaction on employees' overall health (Dirlam \& Zheng, 2017). This is due to the fact that employees who are not satisfied with their work may report higher levels of stress which may affect their overall health. Employees' satisfaction with their jobs is very crucial not only because of the saying that "a satisfied worker is a productive worker" but also because satisfied workers have been known to be healthier than unsatisfied workers. A meta-analysis done by Cass, Siu, Faragher \& Cooper (2005) on employees' job satisfaction and their wellbeing revealed that employees' degree of job satisfaction was positively related to their overall wellbeing. A recent study conducted by Karabati, Ensari and Fiorentino (2019) on employees' job satisfaction and wellbeing confirmed that job satisfaction had a profound impact on employees' wellbeing. Another meta-analysis of 485 studies done by Faragher, Cass \& Cooper (2005) revealed that job satisfaction was significantly related to employees' general health. Specifically, Faragher and his colleagues (2005) further revealed that job satisfaction was more related to employees' psychological problems than their physical health. Further studies (e.g. Bowling, Eschleman \& Wang, 2010; Dirlam \& Zheng, 2017; Fischer \& Sousa-Poza, 2007) conducted on the impact of job satisfaction on employees' psychological wellbeing have all indicated that higher job satisfaction was associated with improving employees' psychological wellbeing. Based on these findings, the following hypothesis was tested;

H5: Employees' job satisfaction will have a significant positive effect on their psychological wellbeing.

\subsection{The Indirect Effect of Supervisor Support on Employees' Psychological Wellbeing via Work-Family Conflict or Job Satisfaction}

Previous studies had reportedly found on one side that supportive supervisors tend to help employees' deal with their work-to-family conflict (Ford et al., 2007; Kossek et al., 2011; Selvarajan et al., 2013; Van Daalen et al., 2006). On the other side, other studies have also reported that employees' conflict with their work roles interfering with their family roles, negatively affect their psychological wellbeing because this type of work/family conflict has been known to cause higher stress to employees (Allen et al., 2000; Frone, 2003; Hill, 2005; Kalliath et al., 2017; Winefield et al., 2014). Based on these findings, one could argue that the degree of support employees received from their supervisor could significantly affect their work-to-family conflict which in turn could affect employees' psychological wellbeing, therefore the following hypothesis was tested;

H6: There will be an indirect effect of supervisor support on employees' psychological wellbeing via 
work-to-family conflict.

Similarly, past studies that explored on supervisor support and employees' job satisfaction have revealed that supportive supervisors significantly and positively influenced employees' job satisfaction because it helps employees to alleviate the stress that might negatively affect their job satisfaction (Alegre et al.,2016; Galletta, Portoghese, Penna, Battistelli, \& Saiani, 2011; Kula \& Guler, 2014; Willemse et al., 2012). On the other hand, some past studies that explored on employees' job satisfaction and their psychological wellbeing have shown that employees' degree of job satisfaction significantly affected their psychological wellbeing due to its effect on employees' stress levels (Bowling et al., 2010; Dirlam \& Zheng, 2017; Faragher et al., 2005; Fischer \& Sousa-Poza, 2007). Therefore, building on these findings, one could argue that the degree of support employees received from their supervisor could result in the level of job satisfaction experienced by employees which in turn could affect employees' psychological wellbeing, hence the following hypothesis was tested;

H7: There will be an indirect effect of supervisor support on employees' psychological wellbeing via job satisfaction.

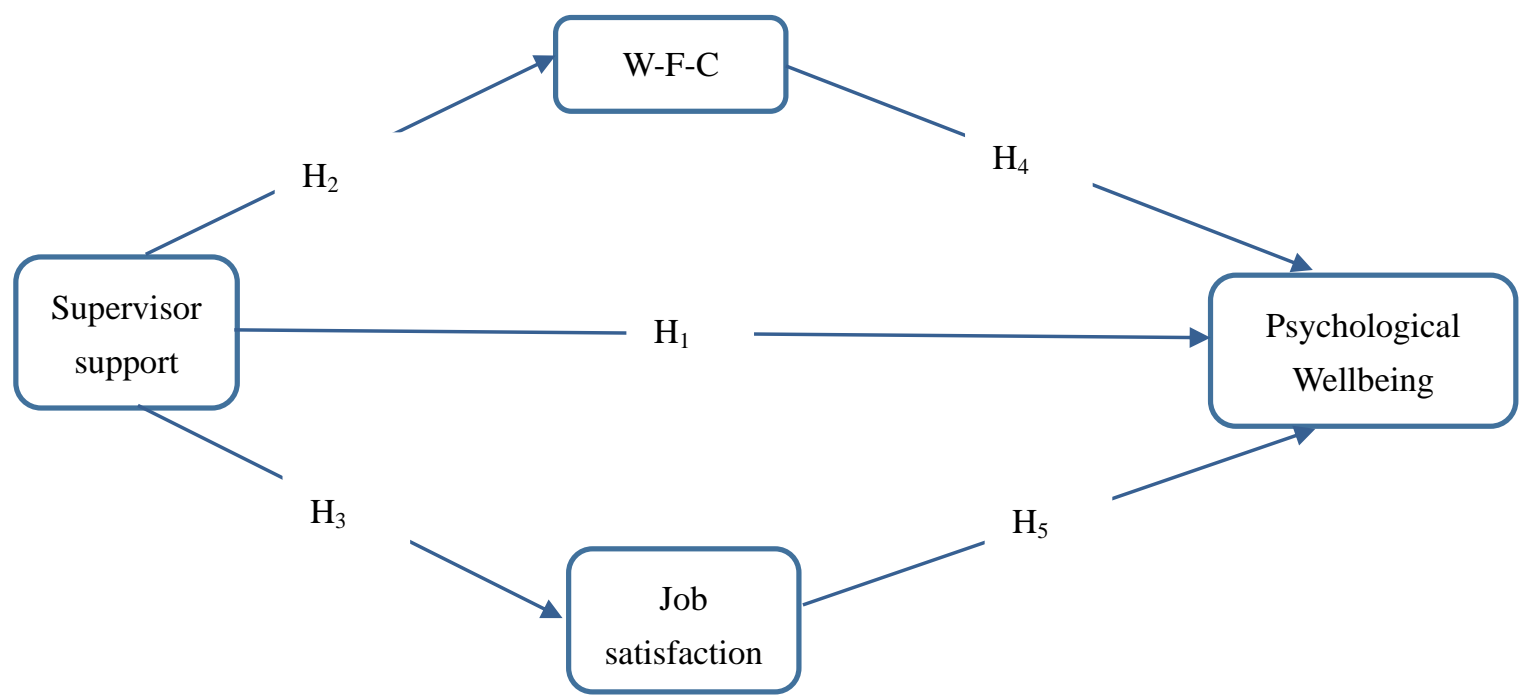

Figure 1. Research model for the study

\section{Research Methodology}

\subsection{Research Design}

The current study utilized a cross-sectional study based on primary data as its research design with a quantitative method of collection of data. Self-administered questionnaires were the type of data collection instrument that was used to measure the constructs of the study and to elicit participant responses.

\subsection{Sample and Sampling Procedure}

The sample of this current study consisted of administrative workers at the University of Cape Coast, Ghana. Simple random sampling was used to gather data on 290 administrative workers. The self-administered questionnaires were administered to participants through online surveys and the drop and collect method. The online survey was developed using Qualtrics and the link was sent to workers through their mails and WhatsApp. Workers who were available in their respective offices were given the questionnaires to fill in person. Out of the 290 administrative workers that responded to the questionnaires, 170 of them were males whiles the remaining 120 were females representing $58.6 \%$ and $41.4 \%$ respectively. The age of participants ranges from 19 to 60 years with a mean age of 28.40 years $(\mathrm{SD}=6.20)$. In relation to marital status, 168 participants $(57.9 \%)$ reported not married while the remaining 122 participants $(42.1 \%)$ reported married.

\subsection{Measures}

Supervisor Support: Perceived Supervisor Support Scale developed by Eisenberger, Huntington, Hutchinson and Sowa in 1986 was utilized to measure employees' supervisor support. The scale consisted of 4 items on a Likert scale of 5 points which ranges from one which is strongly disagree to five which is strongly agree. Higher scores 
denoted higher support received from their supervisors. Samples of the items include: "My work supervisor really cares about my well-being", "My supervisor strongly considers my goals and values", "My supervisor cares about my opinions". The reliability coefficient using Cronbach's alpha for this scale was 0.68 .

Work-To-Family Conflict: Work-Family Conflict Scale by Carlson, Kacmar and Williams (2000) was adopted to measure employees' work-to-family conflict. The scale consisted of 18 items on a Likert scale of 5 pointsstrongly disagree, tend to disagree, neither agree nor disagree, tend to agree and strongly agree- that was scored from one to five. For the present study, 9 items measuring work-to-family conflict were selected. Higher scores specified higher work-to-family conflict. Samples of items are: "My work keeps me from my family activities more than I would like", "I am often so emotionally drained when I get home from work that it prevents me from contributing to my family", "The problem-solving behaviors I use in my job are not effective in resolving problems at home". The reliability coefficient using Cronbach's alpha for this scale was 0.87 .

Job Satisfaction: Job Satisfaction Scale developed by Dubinsky and Hartley in 1986 was adopted to measure employees' satisfaction with their jobs. It consisted of 5 items on a Likert scale of 5 points- strongly disagree, tend to disagree, neither agree nor disagree, tend to agree and strongly agree- that was scored from one to five. Higher scores indicated higher job satisfaction. Examples of items under this scale include: "Generally speaking, I am very satisfied with this job", "I frequently think of quitting this job", "I am generally satisfied with the kind of work I do in this job". The reliability coefficient using Cronbach's alpha for this scale was 0.67.

Psychological Wellbeing: Wellbeing index developed by the World Health Organization in 1998 was adopted to measure employees' psychological wellbeing. The scale is popularly known as the WHO (5) wellbeing index. The scale consisted of 5 items on a Likert scale of 5 points- strongly disagree, tend to disagree, neither agree nor disagree, tend to agree and strongly agree- that was scored from one to five. Higher scores indicated higher quality of life. Samples of items are: "I have felt cheerful and in good spirits", "I have felt calm and relaxed", "I woke up feeling fresh and rested". The reliability coefficient using Cronbach's alpha for this scale was 0.81 .

\section{Results}

\subsection{Validity and Reliability of Measures}

To examine the validity of each of the constructs, a Confirmatory Factor Analysis was used to examine whether all the observed variables that loaded on their latent variables were acceptable to include in the data analysis. Items with a significant factor loading above 0.40 were considered to be good and items below 0.40 were considered unacceptable (Hair, Black, Babin, Anderson \& Tatham, 2006). One item (item 5 of job satisfaction) was deleted due to low standardized factor loading below 0.40 . The reliability of the instruments was assessed using Cronbach's alpha coefficients. The reliability scores range from 0.67 to 0.87 . According to Hair et al. (2006), a reliability score of 0.60 is a threshold that is acceptable.

\subsection{Mean, Standard Deviations and Pearson Correlation}

Means, standard deviations and Pearson correlation were computed to probe the associations among the variables of this current study. Table 2 revealed that there were significant correlations in direction to the research model for this study. Values displayed in Table 1 indicate that positive significant associations were found among supervisor support, job satisfaction and psychological wellbeing. However, a significant negative association was found between work-to-family conflict and supervisor support, job satisfaction and psychological wellbeing.

Table 1. Means, Standard Deviation and Pearson Correlation

\begin{tabular}{lllccc}
\hline Variables & Mean & SD & 1 & 2 & 3 \\
\hline 1. Supervisor support & 3.57 & 0.71 & & & \\
2. Work-to-family conflict & 3.07 & 0.83 & $-0.24^{* *}$ & & \\
3. Job satisfaction & 3.38 & 0.77 & $0.30^{* *}$ & $-0.12^{*}$ & \\
4. Psychological Wellbeing & 3.62 & 0.73 & $0.39^{* *}$ & $-0.19^{* *}$ & $0.42^{* *}$ \\
\hline
\end{tabular}

Note. $* \mathrm{p}<0.05, * * \mathrm{p}<0.01, * * * \mathrm{p}<0.001, \mathrm{~N}=290$

\subsection{Hypotheses Testing}

To test simultaneously for all the six hypotheses formulated in the study, SPSS PROCESS (model 4) was used to 
conduct a parallel mediation analysis to test the model. This type of analysis permits us to test for the direct effects of supervisor support on employees' psychological wellbeing, work-to-family conflict and job satisfaction. Furthermore, it also enables us to test for the effect of employees' work-to-family conflict and job satisfaction on their psychological wellbeing. Lastly, it enables us to test for the indirect effects of supervisor support on employees' psychological wellbeing via work-to-family conflict and job satisfaction. The total effect of supervisor support on employees' psychological wellbeing was statistically significant $(\mathrm{c}=.397, \mathrm{SE}=.055, \mathrm{t}$ $=7.153, \mathrm{p}<.001)$.

4.3.1 Supportive Supervisors' Impact on Employees' Psychological Wellbeing, Work-To-Family Conflict and Job Satisfaction

The results displayed in Figure 2 revealed that supervisor support had a significant influence on employees' psychological wellbeing, work-to-family conflict and job satisfaction signifying that supervisor support had a significant influence on several employees' outcomes. Precisely, the findings shown that supportive supervisors had a significant and positive direct effect on employees' psychological wellbeing $(\beta=.279, \mathrm{SE}=.056, \mathrm{t}=4.999$, $\mathrm{p}<.001)$ and job satisfaction $(\beta=.319, \mathrm{SE}=.061, \mathrm{t}=5.231, \mathrm{p}<.001)$. Thus Hypothesis 1 and 3 were supported. Results from Figure 2, further indicated that the support employees receive from their supervisors had a significant and negative direct effect on employees' work-to-family conflict $(\beta=-.278, \mathrm{SE}=.066, \mathrm{t}=-4.190, \mathrm{p}$ $<.001)$. Hence, Hypothesis 2 was also supported.

\subsubsection{Work-to-Family Conflict and Job Satisfaction as a Direct Antecedent of Psychological Wellbeing}

Concerning the direct effect of employees' work-to-family conflict on their psychological wellbeing, results displayed in Figure 2 show that there was a negative direct effect of work-to-family conflict on employees' psychological wellbeing but the relationship was not statistically significant $(\beta=-.071, \mathrm{SE}=.046, \mathrm{t}=-1.524, \mathrm{p}$ $=.128$ ). Hence, hypothesis 4 was not supported. Conversely, employees' job satisfaction seemed to have a significant influence on their psychological wellbeing. Findings in Figure 2 indicated that employees' job satisfaction had a significant and positive direct effect on their psychological wellbeing $(\beta=.308, \mathrm{SE}=.050, \mathrm{t}=$ $6.10, \mathrm{p}<.001)$. Thus, hypothesis 5 was supported.

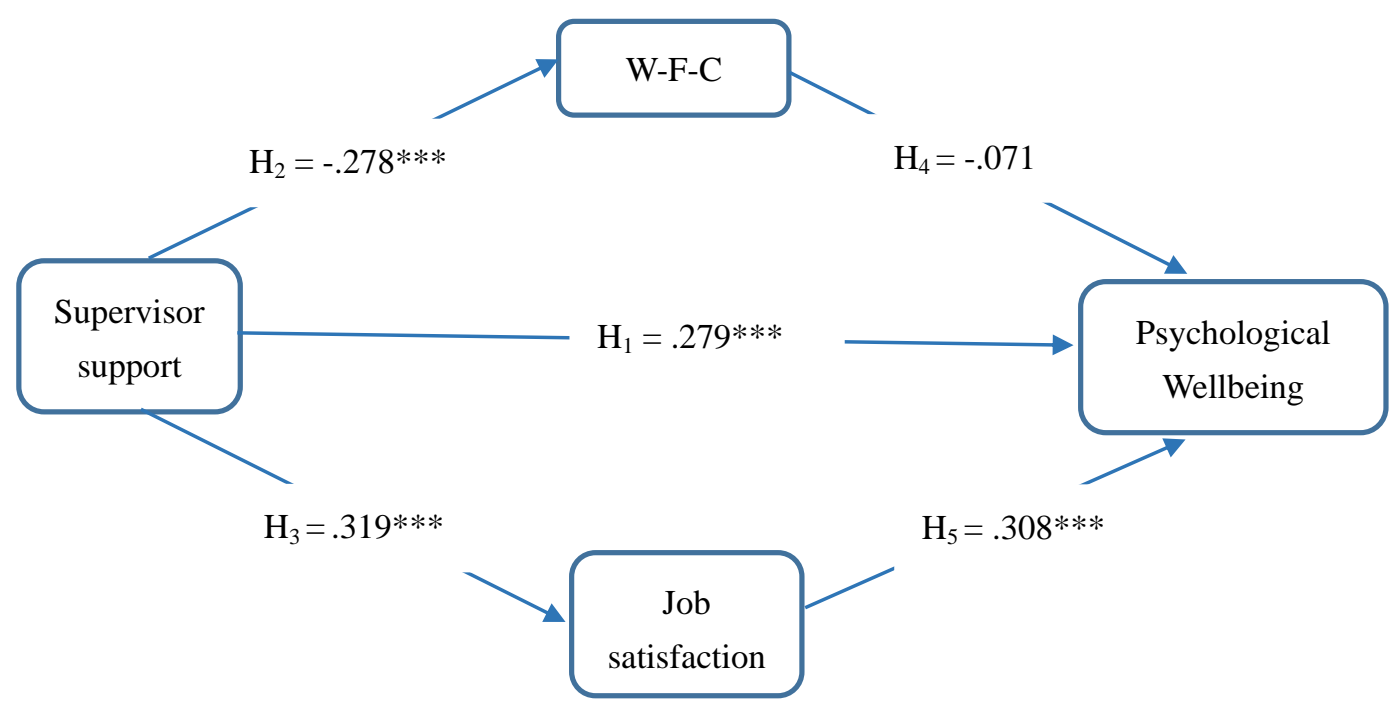

Figure 2. Parallel mediation analysis showing the effect of supervisor support on employees' psychological wellbeing as mediated simultaneously by work-to-family conflict (W-F-C) and job satisfaction

4.3.3 The Indirect Effect of Supervisor Support on Employees' Psychological Wellbeing via Work-To-Family Conflict or Job Satisfaction

Statistical significance of the indirect effects of supervisor support on employees' psychological wellbeing either through work-to-family conflict or job satisfaction was examined over 10,000 bootstrap samples with estimates taken at a 95\% confidence interval. As seen in Table 2, the indirect effect of supervisor support on employees' psychological wellbeing via work-to-family conflict was not statistically significant (Effect $=0.020, \mathrm{CI}$ : -0.006 , 0.051). Hence, hypothesis 6 was not supported. 
Conversely, the indirect effect of supervisor support on employees' psychological wellbeing via job satisfaction was found to be statistically significant. The Bootstrapped effect (with 95\% confidence interval) from the table below showed that the indirect effect of the supervisor's support on psychological wellbeing via job satisfaction was statistically significant $($ Effect $=0.098$, CI: 0.047, 0.160). Hence, hypothesis 7 was supported.

Table 2. The indirect effects of supervisor support on employees' psychological wellbeing via work-to-family conflict or job satisfaction

\begin{tabular}{llccc}
\hline & & & \multicolumn{2}{c}{ 95\%CI } \\
\cline { 4 - 5 } Indirect effects & Effect & SE & LL & UL \\
\hline $\mathrm{SS} \rightarrow \mathrm{W}-\mathrm{F}-\mathrm{C} \rightarrow$ PWB & 0.020 & 0.015 & -0.006 & 0.051 \\
$\mathrm{SS} \rightarrow \mathrm{JS} \rightarrow \mathrm{PWB}$ & 0.098 & 0.028 & 0.047 & 0.160 \\
\hline
\end{tabular}

Note. $\mathrm{CI}=$ confidence; LL=lower limit, UL=upper limit; Model $1=$ Supervisor Support $\rightarrow$ Work-to-family conflict $\rightarrow$ Psychological wellbeing; Model 2 = Supervisor support $\rightarrow$ Job satisfaction $\rightarrow$ Psychological wellbeing.

\section{Discussion}

The main goal of this study was to examine the impact of supervisor support on employees' psychological wellbeing as mediated by work-to-family conflict or job satisfaction. More specifically, the first goal of the study was to test for the impact of supervisor support on employees' work-to-family conflict, job satisfaction and psychological wellbeing. The second goal was to test the effect of work-to-family conflict and job satisfaction on employees' psychological wellbeing. The last goal of the study was to examine the indirect effect of supervisor support on employees' psychological wellbeing either through work-to-family conflict or job satisfaction. Out of the seven hypotheses tested in this study, the findings provided support for five of the hypothesized relationship while the other two hypotheses $(4 \& 6)$ tested were not supported.

\subsection{Summary of Findings}

5.1.1 Supportive Supervisors' Impact on Employees' Psychological Wellbeing, Work-To-Family Conflict and Job Satisfaction

The study findings indicated that employees' support they receive from their supervisors played a vital role in influencing their psychological wellbeing, work-to-family conflict and job satisfaction. Regarding the direct effect of supervisor support on employees' psychological wellbeing and job satisfaction, the findings of this study confirmed that supervisor support had a significant and positive direct influence on employees' psychological wellbeing and job satisfaction. Hence Hypothesis 1 and 3 were supported. The findings of this study concur with several studies that reported that the support employees received from their supervisor had a significant and positive direct effect on their psychological wellbeing (Beehr et al., 2003; Gibson et al., 2009; Gilbreath \& Benson, 2004; Gordon et al., 2019; Hämmig, 2017; Kawachi \& Berkman, 2001; Rana \& Javed, 2019; Willemse et al., 2012) and job satisfaction (Ahmad et al., 2019; Alegre et al., 2016; Gok et al., 2015; Karatepe \& Kilic, 2007; Kula \& Guler, 2014; Quresshi et al., 2018; Quresshi \& Hamid, 2017; Sergeant \& Frenkel, 2000). A possible reason for finding this expected results can be attributed to the fact that supportive supervisor provides guidance, assistance and feedback which assist employees to cope with complex situations that occurs in the workplace, therefore alleviating occupational stress that may negatively affect employees' psychological wellbeing and job satisfaction (Eisenberger et al., 2002). Additionally, workers may feel appreciated, respected and supported when their supervisors tend to be more supportive with them which is very crucial in increasing the degree of job satisfaction and psychological wellbeing.

Concerning the direct effect of supervisor support on work-to-family conflict of employees, the results of this analysis revealed that supervisor support had a significant and negative direct effect on employees' work-to-family conflict as expected, therefore Hypothesis 2 was supported. The findings corroborated with other previous studies (Anderson et al., 2002; Burke \& Greenglass, 1999; Ford et al., 2007; Karatepe \& Kilic, 2007; Kossek et al., 2011; Selvarajan et al., 2013; Talukder, 2019; Van Daalen et al., 2006). A probable reason for getting these expected results may be because supervisor support could be regarded as a form of social support that may assist employees in dealing with issues related to work-to-family conflict. Accordingly, Anderson et al. (2002) and Burke and Greenglass (1999) reported that supervisor support is seen as a form of social support that assisted employees with issues related to work-to-family conflict. Therefore, the findings of this study reinforce 
literature that suggested that supervisor support was an effective way of assisting employees' to deal with their work-to-family conflict.

\subsubsection{Work-to-Family Conflict and Job Satisfaction as a Direct Antecedents of Psychological Wellbeing}

Hypothesis 4 stated that there will be a negative direct effect of employees' work-to-family conflict on their psychological wellbeing. The results of this parallel mediation analysis showed that work-to-family conflict did not have a significant and negative direct effect on the psychological wellbeing of employees. Therefore, this hypothesis was not supported. The findings of the study are contrary to a number of other studies (Allen et al., 2000; Frone, 2003; Hill, 2005; Kalliath et al., 2017; Lu et al., 2006; Obrenovic et al., 2020; Winefield et al., 2014) that reported that work-to-family conflict had a negative direct impact on employees' psychological wellbeing. These unexpected results may be attributed to the fact that there are several other variables that have been known to affect the psychological wellbeing of employees of which some may offset the effects of the other. For example, an employee may be struggling to deal with his or her work-to-family conflict but other aspects such as a supportive supervisor, a good relationship with co-workers, better compensation, favorable working environment, etc. could make the employee very satisfied and happy with his or her work, therefore offsetting the effect of work-to-family conflict on the employees' psychological wellbeing. To test this, a simple linear regression analysis was used to regress psychological wellbeing on work-to-family conflict only. The results showed that there was a significant and negative direct effect of work-to-family conflict on employees' psychological wellbeing $(b=-.16, t(288)=25.37, p=0.002)$. However, regressing psychological wellbeing on work-to-family conflict, job satisfaction and supervisor support simultaneously as already shown in Figure 2, revealed that work-to-family conflict had no significant negative effect on employees' psychological wellbeing. This means that the presence of supervisor support and job satisfaction buffered or nullified the negative effect of work-to-family conflict on employees' psychological wellbeing explaining the reason for these unexpected results.

Regarding the direct effect of job satisfaction on employees' psychological wellbeing, the findings of this study confirmed that employees' job satisfaction had a significant and positive direct effect on their psychological wellbeing. Thus Hypothesis 5 was supported. The findings of this study are consistent with other studies (Bowling et al., 2010; Dirlam \& Zheng, 2017; Fischer \& Sousa-Poza, 2007; Karabati et al., 2019; Page \& Vella-Brodrick, 2009) that reported that employees' job satisfaction was positively related to their psychological wellbeing. This is probably because job satisfaction may affect other areas of an employee's life, therefore, influencing their psychological wellbeing. A meta-analysis conducted by Faragher et al. (2005) revealed that employees' degree of satisfaction they have with their jobs affected employees' levels of burnout, anxiety, depression and self-esteem. Additionally, Dirlam and Zheng (2017) reported a significant positive effect of employees' job satisfaction on their psychological wellbeing due to its effect on employees' stress levels. Therefore we may cautiously conclude that when employees are more satisfied with their jobs, they feel less stressed therefore experiencing less anxiety, depression and burnout which is associated with improving their psychological wellbeing (Fischer \& Sousa-Poza, 2007).

5.1.3 The Indirect Effects of Supervisor Support on Employees' Psychological Wellbeing via Work-Family Conflict or Job Satisfaction

Statistical significance of the indirect effects of supervisor support on employees' psychological wellbeing either through work-to-family conflict or job satisfaction showed that there was an indirect effect of supervisor support on employees' psychological wellbeing through job satisfaction and not work-to-family conflict. Thus, hypothesis 7 was supported but hypothesis 6 was not. The non-significant indirect effect of supervisor support on psychological wellbeing through work-to-family conflict signifies that supervisor support had a direct effect on employees' psychological wellbeing, therefore, confirming the findings of other studies (Beehr et al., 2003; Gibson et al., 2009; Gilbreath \& Benson, 2004; Gordon et al., 2019; Hämmig, 2017; Kawachi \& Berkman, 2001; Rana \& Javed, 2019; Willemse et al., 2012) that found a direct effect between supervisor support and psychological wellbeing. Even though the study findings did not support this hypothesis, it provided support for similar research done by Drummond et al. (2017) who found no indirect effect of supervisor support on psychological strain via work-to-family conflict of employees in New Zealand and Australia. However, Drummond et al. (2017) rather found an indirect effect of supervisor support on psychological strain via work-to-family conflict among employees in China and Hong Kong signifying that national differences could be the reason for finding these unexpected results.

However, concerning the indirect effect of supervisor support on employees' psychological wellbeing via job satisfaction, the study findings indicated that there is a significant indirect effect of supervisor support on 
employees' psychological wellbeing via job satisfaction. The findings further revealed that supervisor support increases the degree of job satisfaction of employees which in turn improves their psychological wellbeing. As predicted by previous studies on one side that supervisor support increases the degree of job satisfaction of employees (Alegre et al.,2016; Galletta et al., 2011; Kula \& Guler, 2014; Willemse et al., 2012) and on the other side that job satisfaction also increases the psychological wellbeing of employees (Bowling et al., 2010; Fischer \& Sousa-Poza, 2007; Page \& Vella-Brodrick, 2009), it was not surprising that the results indicated that job satisfaction mediates the relationship between supervisor support and psychological wellbeing. According to Eisenberger et al. (2002), a supportive supervisor provides guidance, assistance and feedback to employees. This support helps employees to deal with any occupational stress associated with their jobs, making employees more satisfied which may, in turn, be associated with less anxiety, depression and burnout hence improving their psychological wellbeing.

\subsection{Theoretical and Practical Implications}

Theoretically, the study findings offer several contributions to academic literature in this field. Previous studies (Beehr et al., 2003; Gibson et al., 2009; Gilbreath \& Benson, 2004; Gordon et al., 2019; Hämmig, 2017; Kawachi \& Berkman, 2001; Rana \& Javed, 2019; Willemse et al., 2012) have suggested models that hypothesize that supportive supervisors have a significant influence on employees' psychological wellbeing. This study findings seem to be applicable as it reveals that support that employees receive from their supervisors plays a significant and positive impact in influencing their psychological wellbeing. Moreover, the study findings also provide supports to literature (Ahmad et al., 2019; Alegre et al., 2016; Gok et al., 2015; Karatepe \& Kilic, 2007; Kula \& Guler, 2014; Quresshi et al., 2018; Quresshi \& Hamid, 2017; Sergeant \& Frenkel, 2000) that accentuated that supportive supervisor may have a significant and positive effect on employees' job satisfaction. The current study revealed that supervisor support had a significant and positive influence on determining the level of employees' job satisfaction. Lastly, the study findings further provide support in enlightening us on the relationship between employees' job satisfaction and their psychological wellbeing. This study seems to be consistent with academic literature (Bowling et al., 2010; Dirlam \& Zheng, 2017; Faragher et al., 2005; Fischer \& Sousa-Poza, 2007) that accentuated the significant role of job satisfaction on employees' psychological wellbeing. The study findings indicated that employees' satisfaction with their jobs had a significant influence on their psychological wellbeing.

Practically, the results of this present study have significant implications for organizational management, especially for supervisors. The study findings may help organizations in understanding the benefits of supportive supervisors on employees' outcomes in several ways. First, the findings will help organizations who are interested in improving their employees' wellbeing to invest in training their supervisors to be more supportive as this study results indicated that supportive supervisors improve employees' psychological wellbeing. Additionally, increasing supportive supervisors in the organizations could increase employees' job satisfaction which is advantageous for organizational performance and productivity. The current study also revealed that supportive supervisors could help employees' to deal with work-to-family conflict. Furthermore, increasing supportive supervisors could increase employees' levels of job satisfaction which in turn improves their psychological wellbeing. This study demonstrates how significant it is for organizations to invest in training their supervisors to be more supportive in order to improve employees' job satisfaction and psychological wellbeing and to decrease employees' work-to-family conflict.

\subsection{Limitations and Future Research Directions}

The current study as other studies is not without weaknesses. First of all, our research design used in this study is a cross-sectional study. According to Mitchell and Maxwell (2013) conducting a mediation examination using a cross-sectional study often affirms a mediating role by overemphasizing a secondary path through a variable of study which may not be so in multi-wave designs or longitudinal studies. Therefore, making it difficult to conclude causality. Hence, future studies should take this into consideration and conduct studies using a longitudinal or multi-wave design in order to bring to light in-depth information about the stability and changes of study variables over time. Another weakness of our study is the use of a self-reported survey. According to Podsakoff, MacKenzie and Podsakoff (2012), one weakness of self-reported surveys is the tendency of response bias from participants as some participants may overstate or belittle their responses leading to the likelihood of common method biases. Hence, future studies could use other forms of data collection methods such as interviews or multi-rater surveys to avoid this limitation.

\section{Conclusion}

In conclusion, this study contributes to the understanding of the effectiveness of supportive supervisors in 
organizations. More specifically, it focuses on the significance of supportive supervisors on employees' psychological wellbeing, work-to-family conflict and job satisfaction in different ways. First of all, the current study enlightens organizations and practitioners on the extent to which supervisor support is directly related to employees' psychological wellbeing, work-to-family conflict and job satisfaction as the study findings demonstrated that supervisor support had a significant direct effect on employees' work-to-family conflict, job satisfaction and psychological wellbeing. Secondly, this study further provides insights on supportive supervisors and employees' psychological wellbeing via job satisfaction. The study findings suggest that if employees are exposed to supervisors that are very supportive, their job satisfaction will increase which will in turn lead to improved psychological wellbeing of employees.

\section{References}

Ahmad, M. U., Danish, R. Q., Ali, H. F., Shahid, R., Ahsan Khan, M., \& Nadeem, K. (2019). Impact of training and supervisor support on organizational commitment with mediating role of job satisfaction. European Online Journal of Natural and Social Sciences, 8(1), 25-33.

Alegre, I., Mas-Machuca, M., \& Berbegal-Mirabent, J. (2016). Antecedents of employee job satisfaction: Do they matter? Journal of Business Research, 69(4), 1390-1395. https://doi.org/10.1016/j.jbusres.2015.10.113

Allen, T. D., Herst, D. E., Bruck, C. S., \& Sutton, M. (2000). Consequences associated with work-to-family conflict: a review and agenda for future research. Journal of occupational health psychology, 5(2), 278-308. https://doi.org/10.1037/1076-8998.5.2.278

Anderson, S. E., Coffey, B. S., \& Byerly, R. T. (2002). Formal organizational initiatives and informal workplace practices: Links to work-family conflict and job-related outcomes. Journal of management, 28(6), 787-810. https://doi.org/10.1016/S0149-2063(02)00190-3

Beehr, T. A., Farmer, S. J., Glazer, S., Gudanowski, D. M., \& Nair, V. N. (2003). The enigma of social support and occupational stress: Source congruence and gender role effects. Journal of occupational health psychology, 8(3), 220-231. https://doi.org/10.1037/1076-8998.8.3.220

Bowling, N. A., Eschleman, K. J., \& Wang, Q. (2010). A meta-analytic examination of the relationship between job satisfaction and subjective well-being. Journal of Occupational and Organizational Psychology, 83(4), 915-934. https://doi.org/10.1348/096317909X478557

Burke, R. J., \& Greenglass, E. R. (1999). Work-family conflict, spouse support, and nursing staff well-being during organizational restructuring. Journal of occupational health psychology, 4(4), 327-336. https://doi.org/10.1037/1076-8998.4.4.327

Carlson, D. S., Kacmar, K. M., \& Williams, L. J. (2000). Construction and initial validation of a multidimensional measure of work-family conflict. Journal of Vocational behavior, 56(2), 249-276. https://doi.org/10.1006/jvbe.1999.1713

Cass, M. H., Siu, O. L., Faragher, E. B., \& Cooper, C. L. (2003). A meta-analysis of the relationship between job satisfaction and employee health in Hong Kong. Stress and Health: Journal of the International Society for the Investigation of Stress, 19(2), 79-95. https://doi.org/10.1002/smi.959

Dirlam, J., \& Zheng, H. (2017). Job satisfaction developmental trajectories and health: A life course perspective. Social Science \& Medicine, 178, 95-103. https://doi.org/10.1016/j.socscimed.2017.01.040

Drummond, S., O’Driscoll, M. P., Brough, P., Kalliath, T., Siu, O. L., Timms, C., ... \& Lo, D. (2017). The relationship of social support with well-being outcomes via work-family conflict: Moderating effects of gender, dependants and nationality. Human Relations, 70(5), 544-565. https://doi.org/10.1177/0018726716662696

Dubinsky, A. J., \& Hartley, S. W. (1986). Antecedents of retail salesperson performance: A path-analytic perspective. Journal of Business Research, 14, 253-268. https://doi.org/10.1016/0148-2963(86)90005-6

Eisenberger, R., Huntington, R., Hutchinson, S. and Sowa, D. (1986). 'Perceived organizational support'. Journal of Applied Psychology, 71(3), 500-507. https://doi.org/10.1037/0021-9010.71.3.500

Eisenberger, R., Stinglhamber, F., Vandenberghe, C., Sucharski, I. L., \& Rhoades, L. (2002). Perceived supervisor support: contributions to perceived organizational support and employee retention. Journal of applied psychology, 87(3), 565-573. https://doi.org/10.1037/0021-9010.87.3.565

Faragher, E. B., Cass, M., \& Cooper, C. L. (2005). The relationship between job satisfaction and health: a meta-analysis. Occupational Environmental Medicine, 62(2), 105-112. 
https://doi.org/10.1136/oem.2002.006734

Fischer, J. A., \& Sousa-Poza, A. (2007). Personality, job satisfaction and health-The mediating influence of affectivity. University of St. Gallen, Department of Economics Discussion Paper, (2007-31). https://doi.org/10.2139/ssrn.1012025

Ford, M. T., Heinen, B. A., \& Langkamer, K. L. (2007). Work and family satisfaction and conflict: a meta-analysis of cross-domain relations. Journal of applied psychology, 92(1), 57-80. https://doi.org/10.1037/0021-9010.92.1.57

Frone, M. R. (2003). Work-family balance. In J. C. Quick, \& L. E. Tetrick (Eds.), Handbook of occupational health psychology: 143-162. Washington, DC: American Psychological Association. https://doi.org/10.1037/10474-007

Galletta, M., Portoghese, I., Penna, M. P., Battistelli, A., \& Saiani, L. (2011). Turnover intention among Italian nurses: The moderating roles of supervisor support and organizational support. Nursing \& health sciences, 13(2), 184-191. https://doi.org/10.1111/j.1442-2018.2011.00596.x

Gibson, J. A., Grey, I. M., \& Hastings, R. P. (2009). Supervisor support as a predictor of burnout and therapeutic self-efficacy in therapists working in ABA schools. Journal of autism and developmental disorders, 39(7), 1024-1030. https://doi.org/10.1007/s10803-009-0709-4

Gilbreath, B., \& Benson, P. G. (2004). The contribution of supervisor behaviour to employee psychological well-being. Work \& Stress, 18(3), 255-266. https://doi.org/10.1080/02678370412331317499

Gok, S., Karatuna, I., \& Karaca, P. O. (2015). The role of perceived supervisor support and organizational identification in job satisfaction. Procedia-Social and Behavioral Sciences, 177, 38-42. https://doi.org/10.1016/j.sbspro.2015.02.328

Gordon, S., Tang, C. H. H., Day, J., \& Adler, H. (2019). Supervisor support and turnover in hotels. International Journal of Contemporary Hospitality Management, 31, 496-512. https://doi.org/10.1108/IJCHM-10-2016-0565

Greenhaus, J. H., \& Beutell, N. J. (1985). Sources of conflict between work and family roles. Academy of management review, 10(1), 76-88. https://doi.org/10.5465/amr.1985.4277352

Hair, J. F., Black, W. C., Babin, B. J., Anderson, R. E., \& Tatham, R. (2006). Multivariate Data Analysis. Upper Saddle River, NJ: Prentice Hall.

Hämmig, O. (2017). Health and well-being at work: The key role of supervisor support. SSM-Population Health, 3, 393-402. https://doi.org/10.1016/j.ssmph.2017.04.002

Hill, E. J. (2005). Work-family facilitation and conflict, working fathers and mothers, work-family stressors and support. Journal of Family issues, 26(6), 793-819. https://doi.org/10.1177/0192513X05277542

Kalliath, P., Kalliath, T., \& Chan, C. (2017). Work-family conflict, family satisfaction and employee well-being: a comparative study of Australian and Indian social workers. Human Resource Management Journal, 27(3), 366-381. https://doi.org/10.1111/1748-8583.12143

Karabati, S., Ensari, N., \& Fiorentino, D. (2019). Job satisfaction, rumination, and subjective well-being: A moderated mediational model. Journal of Happiness Studies, 20(1), 251-268. https://doi.org/10.1007/s10902-017-9947-x

Karatepe, O. M., \& Kilic, H. (2007). Relationships of supervisor support and conflicts in the work-family interface with the selected job outcomes of frontline employees. Tourism management, 28(1), 238-252. https://doi.org/10.1016/j.tourman.2005.12.019

Kawachi, I., \& Berkman, L. F. (2001). Social ties and mental health. Journal of Urban health, 78(3), 458-467. https://doi.org/10.1093/jurban/78.3.458

Kossek, E. E., Pichler, S., Bodner, T., \& Hammer, L. B. (2011). Workplace social support and work-family conflict: A meta-analysis clarifying the influence of general and work-family-specific supervisor and organizational support. Personnel psychology, 64(2), 289-313. https://doi.org/10.1111/j.1744-6570.2011.01211.x

Kula, S., \& Guler, A. (2014). Influence of Supervisor Support on Job Satisfaction Levels: An Evaluation of Turkish National Police (TNP) Officers in the Istanbul Police Department. International Journal of Criminal Justice Sciences, 9(2), 209-224. 
Lu, L., Gilmour, R., Kao, S. F., \& Huang, M. T. (2006). A cross-cultural study of work/family demands, work/family conflict and wellbeing: the Taiwanese vs British. Career Development International, 11, 9-27. https://doi.org/10.1108/13620430610642354

Mesmer-Magnus, J. R., \& Viswesvaran, C. (2005). Convergence between measures of work-to-family and family-to-work conflict: A meta-analytic examination. Journal of vocational behavior, 67(2), 215-232. https://doi.org/10.1016/j.jvb.2004.05.004

Michel, J. S., Kotrba, L. M., Mitchelson, J. K., Clark, M. A., \& Baltes, B. B. (2011). Antecedents of work-family conflict: A meta-analytic review. Journal of organizational behavior, 32(5), 689-725. https://doi.org/10.1002/job.695

Mitchell, M. A., \& Maxwell, S. E. (2013). A comparison of the cross-sectional and sequential designs when assessing longitudinal mediation. Multivariate Behavioral Research, 48(3), 301-339. https://doi.org/10.1080/00273171.2013.784696

Obrenovic, B., Du Jianguo, A. K., \& Khan, M. A. S. (2020). Work-family conflict impact on psychological safety and psychological well-being: A job performance model. Frontiers in psychology, 11, 1-18. https://doi.org/10.3389/fpsyg.2020.00475

Page, K. M., \& Vella-Brodrick, D. A. (2009). The 'what', 'why'and 'how'of employee well-being: A new model. Social indicators research, 90(3), 441-458. https://doi.org/10.1007/s11205-008-9270-3

Plaisier, I., de Bruijn, J. G., de Graaf, R., ten Have, M., Beekman, A. T., \& Penninx, B. W. (2007). The contribution of working conditions and social support to the onset of depressive and anxiety disorders among male and female employees. Social science \& medicine, 64(2), 401-410. https://doi.org/10.1016/j.socscimed.2006.09.008

Podsakoff, P. M., MacKenzie, S. B., \& Podsakoff, N. P. (2012). Sources of method bias in social science research and recommendations on how to control it. Annual review of psychology, 63, 539-569. https://doi.org/10.1146/annurev-psych-120710-100452

Qureshi, M. A., \& Hamid, K. (2017). Impact of supervisor support on job satisfaction: A moderating role of fairness perception. International Journal of Academic Research in Business and Social Sciences, 7(3), 235-242.

Qureshi, M. A., Ab Hamid, K. B., Jeihoony, P., Ali, R., Brohi, N. A., Magsi, R., \& Shah, S. M. M. (2018). Is supervisor support matter in job satisfaction? A moderating role of fairness perception among nurses in Pakistan. Academy of Strategic Management Journal, 17(6), 1-10.

Rana, F. A., \& Javed, U. (2019). Psychosocial job characteristics, employee well-being, and quit intentions in Pakistan's insurance sector. Global Business and Organizational Excellence,38(4), 38-45. https://doi.org/10.1002/joe.21933

Ryan, R. M., \& Deci, E. L. (2001). On happiness and human potentials: A review of research on hedonic and eudaimonic well-being. Annual review of psychology, 52(1), 141-166. https://doi.org/10.1146/annurev.psych.52.1.141

Sekaran, U. (1985). The paths to mental health: An exploratory study of husbands and wives in dual-career families. Journal of Occupational Psychology, 58(2), 129-137. https://doi.org/10.1111/j.2044-8325.1985.tb00188.x

Selvarajan, T. T., Cloninger, P. A., \& Singh, B. (2013). Social support and work-family conflict: A test of an indirect effects model. Journal of Vocational Behavior, 83(3), 486-499. https://doi.org/10.1016/j.jvb.2013.07.004

Sergeant, A., \& Frenkel, S. (2000). When do customer contact employees satisfy customers? Journal of Service Research, 3(1), 18-34. https://doi.org/10.1177/109467050031002

Shrout, P. E., \& Bolger, N. (2002). Mediation in experimental and nonexperimental studies: new procedures and recommendations. Psychological methods, 7(4), 422-445. https://doi.org/10.1037/1082-989X.7.4.422

Sinokki, M., Ahola, K., Hinkka, K., Sallinen, M., Härmä, M., Puukka, P., ... \& Virtanen, M. (2010). The association of social support at work and in private life with sleeping problems in the Finnish health 2000 study. Journal of Occupational and Environmental Medicine, 52(1), 54-61. https://doi.org/10.1097/JOM.0b013e3181c5c373

Talukder, A. M. H. (2019). Supervisor support and organizational commitment: The role of work-family conflict, 
job satisfaction, and work-life balance. Journal of Employment Counseling, 56(3), 98-116. https://doi.org/10.1002/joec.12125

Van Daalen, G., Willemsen, T. M., \& Sanders, K. (2006). Reducing work-family conflict through different sources of social support. Journal of Vocational Behavior, 69(3), 462-476. https://doi.org/10.1016/j.jvb.2006.07.005

Weiss, H. M. (2002). Deconstructing job satisfaction: Separating evaluations, beliefs and affective experiences. Human resource management review, 12(2), 173-194. https://doi.org/10.1016/S1053-4822(02)00045-1

Willemse, B. M., de Jonge, J., Smit, D., Depla, M. F., \& Pot, A. M. (2012). The moderating role of decision authority and coworker-and supervisor support on the impact of job demands in nursing homes: A cross-sectional study. International Journal of Nursing Studies, 49(7), 822-833. https://doi.org/10.1016/j.ijnurstu.2012.02.003

Winefield, H. R., Boyd, C., \& Winefield, A. H. (2014). Work-family conflict and well-being in university employees. The Journal of psychology, 148(6), 683-697. https://doi.org/10.1080/00223980.2013.822343

Wright, T. A., \& Cropanzano, R. (2000). Psychological well-being and job satisfaction as predictors of job performance. Journal of occupational health psychology, 5(1), 84-94.

https://doi.org/10.1037/1076-8998.5.1.84

\section{Copyrights}

Copyright for this article is retained by the author(s), with first publication rights granted to the journal.

This is an open-access article distributed under the terms and conditions of the Creative Commons Attribution license (http://creativecommons.org/licenses/by/4.0/). 